\title{
The Interview as a Reflective Tool in Preschool Female Teachers' Work with Children from Different Cultures Significance of Communication and Acquiring Hebrew in Preschool
}

\author{
Yosy Mamman, Janan Faraj Falah, Ronit Shlush-Levy \\ The Arab College for Education, Haifa, Israel \\ Email: jananf81@gmail.com
}

How to cite this paper: Mamman, Y., Falah, J. F., \& Shlush-Levy, R. (2019). The Interview as a Reflective Tool in Preschool Female Teachers' Work with Children from Different Cultures Significance of Communication and Acquiring Hebrew in Preschool. Creative Education, 10, 700-713. https://doi.org/10.4236/ce.2019.104052

Received: February 11, 2019

Accepted: April 14, 2019

Published: April 17, 2019

Copyright $\odot 2019$ by author(s) and Scientific Research Publishing Inc. This work is licensed under the Creative Commons Attribution International License (CC BY 4.0).

http://creativecommons.org/licenses/by/4.0/

\begin{abstract}
In this article, the theoretical background was chosen to focus on three directions: the first, reflective thinking as a professional need, as the focus of this research is the reflection the staff performs during the in-depth interview while referring to the immigrant child's difficulties and coping with the new environment, and the coping of the staff working with the children and their families. The second, broad reference to the significance of communication and acquiring the Hebrew language in preschool is during the encounter with a new, foreign environment. We will also address the significance of developing social efficacy skills, which immigrant children need in order to function in preschool and develop as a mature person in the new country.
\end{abstract}

\section{Keywords}

Teachers, Preschool, Different Cultures

\section{Reflective Thinking as the Preschool Teacher's Professional Need}

$21^{\text {st }}$ Century characteristics such as innovativeness, dynamics and pluralism have created an era where knowledge is not perceived as final and determined, but rather, as changing. This requires capabilities for successful functioning in a changing environment. Like other professionals, life and work experience enable preschool teachers to reach new insights about themselves and the world around them and refer to reality from a variety of perspectives (Zedan \& Falah, 2018). 
As mentioned before, anyone experiencing a change faces the need to cope with it in way of reflecting on one's work, a principle guiding self-evaluation based on a professional thinking process as a starting point. Questions such as what information is required for performing a task, and which cognitive processes that an educator undergoes in the course of work, have led to the acknowledgement of professional thinking as grounds for shaping behavior and an interest in the teacher's reflective capabilities during the educational activity. According to this approach, no professional activity can take place without this understanding (Schon, 1983, 1987, 1991; Keiny, 1994). Furthermore, the contribution of the educator's self-awareness of what is happening in his/her environment to the development of other reflective skills is emphasized (Letiche, 1988; Grumet, 1990). Others emphasize learning from previous experiences as significant in the process of educators' professional development (Clandinin \& Connelly, 1991; Calhoun, 1994).

The preschool teacher's reflection ought to be an integral part of her daily routine and constitute a significant junction in her professional development and her status as a learner. The complexity of the preschool teacher's work arises from the encounter between theory and practice. Regarding this encounter, there are two basic approaches: one regards preschool teaching as an applied science, meaning movement from theory to practice, and the development of the ability to apply the theoretical knowledge gained through studies; the second approach regards teaching as a reflective occupation, meaning movement from practice to the theory and encouraging reflective activity around the act of teaching on all its stages and aspects. The common denominator between these two approaches is the fact that both involve the practicing preschool teacher. It has to be noted that an Israeli preschool teacher does not have a way of sharing her knowledge and everyday work, and so self-reflection on her work is of great significance, as she has to take many decisions which are of importance both to her and to the children and their families.

\section{Significance of Communication and Acquiring Hebrew in Preschool}

Entry into the preschool stag constitutes a significant change in the life of the child and may cause a crisis. That is when the child acquires skills and capabilities which depend on adults. The adults accompany the child tangible experiences with are significant explanation and direction. Hence, communication with the environment and acquiring local language are of the utmost significance for immigrant children, with implications on their adjustment to the new environment. In their article, "The Joy of Absorption and Its Difficulties", Haft and Zilberberg argue preschool teachers regard preschool as a framework absorbing children from a variety of cultures, but they emphasize their own language communication difficulties with parents, such as when they have to explain preschool regulations (opening and closing times, schedule and payments), 
and with the children who manifest difficulties finding their way around, difficulties understanding stories, conversations, instructions and basic concepts in Hebrew. The outcome, according to the teachers is meager: often, immigrant children feel lonely, sad and outcasts.

Olstein (1991), in her research "Hebrew is a Hard Language foe Preschool Children", referred to such questions as: Does a new immigrant child absorb the Hebrew language faster when there are optimal conditions in preschool? What are the ways the children take to learn the language faster? What can the education system do to advance the children? Olstein argues that a child entering preschool "is thrown into" a new children's society" and hence, the child communicates in the following manner: first the child tries to explain his/her wishes in the mother tongue. When nit understood, the child attempts using mime, and then acquires some basic words (my, water, no, yes, enough) to communicate with the environment, and hence, Olstein suggests the child has to be taught basic words and expressions in Hebrew, that veteran preschool children help, and the immigrant child encouraged to integrate into their circle. An additional suggestion is to use a mediator-a person who speaks the immigrant child's mother tongue. In her article "Воспитательница-Israeli Preschool Teachers through the Eyes of Originally CIS Parents", Sever (2000) attributes great significance to respect of cultural diversity and recognizes the need to preserve the immigrant's culture of origin. At the same time, she claims planning is the key to respectful absorption and writes,

Preschool teachers realize they are doing hard, important work and are willing to make any necessary effort. I am certain educational teams impart the basics to both children and their parents, thus alleviating their absorption. They will master Hebrew and consider Jewish contents as part of their heritage, without neglecting their cultures of origin.

Horowitz, Shamay and Iltov (2003) detail parental attitudes to preschool and policy which has developed in the community regarding absorption in preschool, in their book, "Absorption and Empowerment-Veterans and Immigrants in Katzrin", in order to overcome the problems of integrating immigrant children into preschool; it was decided to operate in two ways: integrate mediators into preschools and operating day summer camps for immigrant children. The mediator's role is defined by the Katzrin program's coordinator:

The program's goal was to narrow cultural gaps between the immigrants and the teachers' staff. The mediator saw the need to help immigrant children acquire new communication tools. She helped the preschool teacher to get to know the immigrant parents. She handled specific children's problems and focused on their acquiring language and behavior patterns of children in Israeli society. She also tried to initiate parents-teachers' encounters, which have not succeeded as immigrant parents failed to see the instrumental need for them (p. 155).

An additional strategy was a day summer camp held in one of the preschools, in a loved, familiar environment. In that framework, teachers and counselors started treating the children as immigrants. A bi-lingual team helped the child- 
ren make up materials learnt throughout the year, and they learnt it in two languages. At the same time, Israeli teachers learnt about Russian culture. Communication between the teachers and the parents was maintained via a notebook, where parents received, written in Russian, tasks to do with the children. Using the notebook, parents participated in the guidance of their children and developing the learning habits required in the Israeli preschool. In addition, parents received detailed reports of their children's progress and were invited to the end-of-camp party (Ibid, p. 156).

\section{Significance of Developing Social Skills in Preschool}

An additional significant aspect of preschool is the social aspect. A person is an integral part of society. Therefore, a person is expected to behave in accordance with the norms of society. Social skills in early childhood is an issue that receives a good deal of professional attention (Becker, 2009), and is defined as effective inter-personal interaction, as stated, can be identified in early childhood. For instance, the ability to regulate behavior in front of the peer group in the course of social interaction (Denham, 2010), especially when children who are perceived as outcasts are concerned, as immigrant children feel when they need the adults' help to improve their status in the peer group. This begets the professional need for an early childhood intervention program based on understanding the processes which support the child's social compatibility. Such an intervention program may help immigrant children and even improve the behavior of all the preschool children (Becker, 2009).

Social efficacy is closely linked to emotional efficacy which is essential in the creation of interpersonal interaction and developing relationships with others. In this way, a child's ability to respond emotionally and at the same time strategically use emotional knowledge and be aware of his/her influence on the other children. From the child's perspective, the child undergoes a process of socialization. Socialization is a process whereby one learns to know, understand and accept customs, standards, traditions and the culture in which one lives, so also function in a way that suits the needs of society and actively cooperate with its members. Turning the individual into a member of society is done with the help of "secondary socialization agents": preschool teachers, friends in the peer group, neighbors and the mass media. As stated earlier, children aged 3 - 5 spend many hours a day in preschool, and so, the teacher, the assistant and the children are all significant socialization agents for them. Moreover, many children's entry from a different culture to preschool and their encounter with a language, new customs and a new environment require the education system's proper preparation in general and the preschool staff's commitment to the absorbed child's ultimate development (Zino \& Zur, 2009).

\section{Research Methodology}

The research is qualitative. Thus in a "holistic" approach, the researcher is interested in exposing the inner world of the "members of a culture", learn about it 
and understand it from their perspective (emic approach). According to this approach, the origins of behavior lie in definitions, beliefs and ideologies of the "participants" (Pelto \& Pelto, 1978). The methodology is based on the use of ethnographic research tools for gathering and analyzing data. Therefore, Ronit engaged in content analysis of documents of various types, describing the preschool and the interactions taking place in it. Most of the fieldwork consisted of in-depth interviews with the preschool staff (teachers, assistant, psychologist, and immigration mediator). The preschool where the research was conducted was in the town of "Kedem" (false name due to ethical considerations). The town's population is 7000; most of the residents are Israeli born, who had reached the place some 34 years ago, and some are immigrants from the CIS, South America and South Africa. There are four schools in "Kedem"-a State young division (preschool-second grade), a religious state young division (preschool-second grade), a primary school (grades $3-6$ ) and a Junior and High School. In terms of age, there are 9 kindergartens in the community. The preschool where this research was conducted belongs to the state schools.

The interview constitutes a strategy seeking to cause interviewees to talk about their experiences reflectively (Spradley, 1979). Therefore, Ronit held in-depth interviews with five staff members in the same preschool (Table 1).

It should be noted that the mediator is also a new immigrant, who has, in time, acquired mastery of Hebrew. Ronit conducted structured interviews with the staff-she prepared a list of questions in advance and asked them according to their order of appearance in the following list:

1) Immigrant children's difficulties and coping

a) Define the term "adjustment".

b) What are the immigrant child's adjustment difficulties?

c) How does the child cope with these difficulties?

d) Describe the other preschool children's responses to the immigrant child's behavior.

e) What is the significance of time in the immigrant child's adjustment process?

2) Your Difficulties and coping strategies as member of the preschool staff

a) How do you cope with the immigrant child's adjustment difficulties?

b) Describe the conflicts you have encountered in your work with populations from different cultures (the children, the parents).

Table 1. Interviewees distribution.

\begin{tabular}{cccccc}
\hline No & False Name & Age & Role & Seniority in Years & Education \\
\hline $\mathbf{1}$ & Shalva & 50 & Teacher & 30 & B. A. Education \\
$\mathbf{2}$ & Rina & 51 & Assistant & 20 & Early Childhood Course \\
$\mathbf{3}$ & Leah & 55 & Substitute Teacher & 33 & Non Academic Teacher \\
$\mathbf{4}$ & Danya & 40 & Immigrants' Mediator & 10 & Community Work Course \\
$\mathbf{5}$ & Sandra & 42 & Psychologist & 20 & M. A. Psychology \\
\hline
\end{tabular}


c) Propose ways of improvement to the various involved factors.

d) What is your "credo" regarding the absorption of new immigrants.

\section{Findings (Reflective Perspective of Preschool Staff) Difficulties and Coping of Immigrant Children in Preschool}

\subsection{Definition of "Adjustment"}

Each of the members of the preschool staff proposes a different definition of the term "adjustment". The teacher refers to the outcome, "when the child feels comfortable in the environment." In contrast, the substitute teacher regards adjustment as communicative ability, "The ability to communicate with the environment despite language limitations, without words, but with looks." The assistant emphasized the significance of the social aspect, "a state where a child enters a new society and is absorbed in it. How does it happen? How long does it take? What does the child give? What does the child get?" The psychologist explained that adjustment is a kind of personal adaptation capability, "You adapt to a variety of situations, to different factors and rules in each situation." The immigration mediator regarded adjustment as a process whereby the child and the parents are partners, "It depends on the child's personality and the parents' support, and hence there are children who experience difficulties, and there are those who adjust faster."

\subsection{The Immigrant Child's Difficulties}

The staff members are in agreement regarding the fact that no knowing Hebrew constitutes a major obstacle in the immigrant child's adjustment, and the psychologist and assistant provide the following explanation: when the immigrant child comes from a different state, where no Hebrew is spoken, the child experiences difficulties in expression and, and has difficulty in communicating with the environment; the child can neither integrate nor adjust, and society neither explain things nor help, as they do not master the child's mother-tongue. "Sometimes the child pushes and hits and grabs things, because no one understands him. Sometimes the child speaks the mother tongue, and the children do not understand him". The mediator demonstrates the difficulties via the following example: "The child who has difficulties in Hebrew does not understand, does not listen; he is not willing for the parents to speak Hebrew at home, though he masters the mother tongue. Although I have been working with him for a long time, about a year, there are still difficulties, and he was referred to the psychologist and to a therapist engaging in language separation. This is a state where one language does not let another language be acquired and absorbed." According to the teacher, the immigrant child's entry into the children's society is enabled ones the child acquires Hebrew: "When the child started understanding Hebrew, she adjusted to preschool and even enjoyed the children's company, played with them and participated in all the activities, and even communicated 
with the adults."

An additional difficulty arising from the interviewee's statements is the fact the immigrant child does not know the preschool children. This may make the immigrant child cry, remain silent or become confined, "The child cries as he does not know the children, and that is why he is mad at them, and at the adults. Sometimes he just sits in a corner without doing anything, and even refuses to eat, hits children and even tries to run away." The substitute teacher presents another example, "The child arrived in preschool a day after he had landed from the CIS. He shoved children, he shoved us, he rejected our hugs, he cried almost every day although he only spend a part of the day in preschool."

An additional difficulty experienced by immigrant children is not accepting the preschool's regulations and boundaries. The psychologist explains it as arising from the difference between educational norms accepted in the country of origin and the reality of the new country. "There are difficulties in the child $s$ behavior as a far as accepting the mentality, the reality, the rules and regulations of the new environment-preschool. Education here is different from that in the country of origin." According to the mediator, the above difficulty can also be attributed to another reason, "Many immigrant children grow up with their grandparents at home until the age of 3, and only then do they enroll in preschool, and encounter the children's society. This makes it harder for them to integrate and adjust to preschool and the children, and hence, they do not accept the rules and regulations."

\subsection{Immigrant Children's Coping with Difficulties}

The staff described the immigrant children attempts to successfully cope with the difficulties. The substitute teacher notes children who "examine the environment suspiciously, observe and test the responses of the environment and of the adults. In the beginning they try to study the environment by observing." Whereas the mediator describes children "who manage on their own and do not ask for help, and even communicate by using sign language." The teacher and substitute teacher's statements are interesting, describing a child who has successfully adjusted through a "mediator": "Some children look for a child, who speaks their language, and connect to him and play with him, or a friend with who they feel comfortable and safe, and so they start taking part in the various activities, playing with dolls, cubes, painting, looking at the books and so forth." They also tell of one immigrant child who "is at his best in music, sports and computer lessons."

\subsection{Preschool Children Responses to the Immigrant Child's Behavior}

The psychologist and the mediator believe the children's responses to the immigrant child derive from the latter's behavior. "If the child is nice and quiet, there are no problems; the children accept him and integrate him, and he absorbs the language and the codes, and the culture and mentality without any difficulties. 
They help him, talk to him and take him in... and if the child has difficulties, the children accept him differently. Such a child is threatening, and then it is hard to cope with him and he will be rejected by the children, which will increase his difficulties."

In contrast, the teacher and the substitute teacher explain that the attitude to the immigrant child is a direct outcome of the preparation work, "When the children are prepared for absorbing the immigrant child, they are willing to help, accept, embrace, and help... we accept each child gladly, not only immigrant children. We try to help each child and help the children become familiar with the premises. We try to be most positive in our attitude to the immigrant child."

The assistant's description reveals that the staff is helped by veteran immigrant children for translation and as culture mediators, "Children who speak the language help and translate the language of the children and the teachers' explanations. One of the children also goes to the new immigrant's child's home to play and help the new child integrate into society, and we all make drawings and give him sweets."

\subsection{The Significance of Time in the Adjustment Process}

The staff members are in agreement regarding the significant role of time in the immigrant child's adjustment to preschool. They believe a period of one year is the time required for adjustment, and in their statements, they describe the immigrant child after one year of adjustment to the new preschool. At the same time, they set criteria for successful adjustment. The teacher attributes significance to reports of learning she gets from the primary school absorbing the children, "In most cases, first grade teachers report language absorption, good learning of reading and writing. The immigrant children manage to overcome all setbacks and are rather successful."

In contrast, the substitute teacher and the mediator refer to the profile of the Israeli child, "An Israeli child from all perspectives-speaks, Hebrew, has friends and loves the school activities... and knows all the holidays. Children whose parents cooperated and were involved, have adjusted fast and integrated very well." The psychologist and the assistant emphasize the changes in the immigrant child's state of becoming familiar with the local norms, which are new for him/her, "Time is of the greatest significance and contributes to adjustment. Immigrant children arrive with their own codes, and have to get to know the new ones. After a year I see they know the rules, the customs and norms of society... the restrictions and the mentality... time has a good influence on adjustment."

\section{Difficulties and Coping of Immigrant Children in Preschool}

\subsection{Coping with the Immigrant Child's Adjustment Difficulties}

The staff members state that whenever they identified immigrant children's ad- 
justment difficulties, they would have a conversation with the parents with the help of a translator as seen in the following statement, "I approached the parents and talked to them through the mediator, the assistant or someone else who speaks the language, so as to explain the mentality, the language and the culture to them and to the child... to explain the codes of Israeli society." However, we found from the interviews that each staff member used a different strategy for coping with immigrant children's adjustment difficulties. The assistant emphasizes the significance of calming the child, "I soothed, hugged, offered some water and offered a sweet." In contrast, the teacher notes the significance of follow up on the child in preschool and at home, "It is important to follow up on the child s progress and adjustment to the new environment throughout the year, and it is also important to visit the home so as to get to know the environment in which the child grows and reach the family in a less formal way." The teacher emphasizes the social perspective, the immigrant child's association with the preschool children, "It is important that the children help the immigrant children, play with them and share the activities with them, and it is important to look for friends or neighbors with whom the immigrant children can play in the afternoons." The mediator, in her turn, regards the immigrant child's adjustment caught between all the factors, "I have visited the child's home and talked to his parents; I coordinated expectations with the teacher regarding cooperation with the parents. I was assisted by the psychologist, the Karev Foundation mentor and the Department of Education, other mediators and my mentor."

The psychologist also advocates mediation between preschool and the home, and at the same time she seeks to understand and resolve the immigrant child's adjustment difficulties, "Trying to assess why there is a wall between the child and a certain factor, who builds the wall? Examining how the gap between the staff and the child and between the staff and the parents can be bridged. We ought to understand the child s concepts, and sometimes his language. For instance, a child came to school once and told the teacher that his mother had left home. The teacher tried to find out if I knew anything about it, whether there were difficulties at home. Whether the parents had separated or divorced. It turned out the child said 'left' but meant what had happened-the mother went on a trip for a few days. Therefore, it is important to make sure we understand the terms the child is using."

\subsection{Conflicts Working with a Population from a Different Culture}

Most staff members (teacher, psychologist, and mediator) note that during the workday, they face a variety of conflicts. First-clothing. The mediator says, "Some of the parents dress their children in layers, as was the habit in their country of origin, and find it hard to understand and accept the customs of this country." The second conflict is the food the child brings to preschool. The teacher explains, "The parents send the child with a sandwich with cheese and sausage, and I have to explain that we are not allowed to mix meat and cheese... there is a need in our society to change the child s habits and make sure he/she 
drinks a lot." An additional conflict mentioned by the teacher is the child's spoken language, "The child arrives with his mother tongue. Since I speak neither Russian nor Spanish or Amharic, it was hard to communicate with the children and their parents." Regarding the language, the mediator points to another problem, "Some children do not want to speak Hebrew." And the substitute teacher adds, sometimes, because of lack of communication she is embarrassed, "Should I keep the child in school, crying or have the parents take him home, is it Ok to let him cry until he calms down or try to reach him although he rejects me?"

The mediator's statements reflect another conflict-the immigrant child does not participate in preschool events, "Immigrant parents do not understand the significance of parties and other activities and we have to convince them to take part in the activities despite their difficulties in understanding Hebrew and their distance from Israeli culture and Judaism." The teacher and the psychologist share another conflict with which they have to cope-the schedule, "There is a certain schedule in preschool, and the child has to accept it... the immigrant child still has no idea where he is. On the one hand, there is one culture at home and a different culture outside the home. At home, the child may go to sleep at 9:00 p.m., while in preschool, the parents are asked to make sure their children go to sleep early. There is no right or wrong, it is simply because of differences in culture." An additional conflict arising from the psychologist's statements is that of leaving the child alone at home. For instance, "a child from Argentina is very independent; the parent leaves him alone at home with his brother. In Israel, educators argue it is wrong to leave the child alone at home, unattended, which leaves me with the question- which is the right thing, the culture and mentality of the Immigrants from Argentina or Israeli education? Should we explain the significance of hat is desired, or should they just live life as they know it?"

The mediator claims that immigrant parents tend to leave a sick child at home for long periods of time, "When a child is absent for a long time, parents have to be told that in Israel children do not have to be absent for such a long time. On the other hand, this is their mentality, which leads them to believe it is right to keep the child at home until full recovery." In contrast, the assistant claims she has not encountered any conflicts in her work as she speaks the Russian language "and so I understand their mentality. I have gained a lot of experience absorbing immigrant children."

\subsection{Suggestions for Improvement}

The staff's suggestions for improvement focus on the human factor. The first suggestion (substitute teacher, mediator) pertains to the immigrant child absorbed in preschool, "Show a good deal of patience, not to rush and not to exert pressure. Let the child advance at his pace, and not under pressure. Give him his own, personal time." Other suggestions refer to the relationship with the immigrant child's parents, "Sometimes, when parents find it hard to accept the culture and the mentality, we ought to work with them, and then the child may find 
it easier to cope with the difficulties. We have to work with the parents so they spend some more time in preschool with the child, and be more patient."

An irregular suggestion is made by the substitute teacher, who points to the parents of immigrant children who have been absorbed already as support factors, "They speak the language, and in addition, they are new immigrants who have already been absorbed, and perhaps they can offer solutions and help."

The staff members make suggestions pertaining to the veteran preschool children as well. One suggestion-preparing for the arrival of the immigrant child (mediator, assistant), " $A$ few days before the child arrives, it is important to explain to the children that a new child is about to come, tell about the child $s$ country of origin, and mention the fact the child speaks no Hebrew and we have to help him/her integrate." Another suggestions pertains to nurturing their readiness to support the immigrant child socially (teacher, assistant, substitute teacher, mediator), "We will encourage the children to play games, and participate in the activities so they feel partners in preschool. We can also pair them with children who speak their mother tongue so they can help them and talk to them so they can understand. The children can also learn a few words with a dictionary we will prepare for preschool, and find neighbors and friends that will integrate them into the neighborhood and invite them to visit the homes of veteran Israelis."

The staff members emphasize the significance of their cooperation with each other and with other factors, "Our cooperation has to be with everyone-among us and with other professionals, we have to share our deliberations with occupational therapists, speech therapists and other mediators in other organizations."

\section{Credo Regarding Immigration Absorption}

Analysis of the interviews reveals that the main message in the preschool staff's statements (teacher, assistant, substitute teacher, mediator) are directed at the micro level, meaning the absorption of the immigrant child into preschool. Thus, the teacher maintains investment in the immigrant child creates comfortable grounds and a positive atmosphere for the absorption of another immigrant child in the future, "We have to think how to accept them in the best possible way with as little trauma as possible. I think, we in the education system try to do that. Those who have already been absorbed are our ambassadors for the encouragement of absorbing other immigrant children." The substitute teacher and the assistant emphasize the contribution, the absorption's benefit to the veteran, absorbing children, "Regarding the absorption of children, it helps the veteran Israeli children to give of themselves, to contribute to others, to get to know people and be sensitive to the difficulties of others. The children have to be absorbed in the best way possible, and if both sides o not want it, the work will be in vain."

In contrast, the psychologist and the immigration mediator also convey a message on the macro level. The former addresses her credo to the absorbing Israeli society, "The process which the immigrant undergoes is a difficult one. 
When help is no longer provided, real life begins. Sometimes people generalize by saying all those from Argentina are nice, all the Russians are opportunists. We have to accept each person, each immigrant as an individual. It is also important to know, when absorbing a new immigrant, where he or she came from, know about the culture of origin." The mediator directs her beliefs at the new, absorbed immigrants, "The new immigrant has to accept us, and we have to accept him/her. This is the land of all Jews. The immigrant has to accept the reality of this country and has to adjust to the society here, to the culture, learn the language and Israeli mentality."

\section{Conclusion}

The relationship with the preschool's staff had to be such that when they were invited to participate in the research, they would take it naturally and as part of their professional advancement process. This relationship included the creation of circumstances that would allow for reflection on the process of absorbing immigrant children in preschool, on the problems and the achievements of this absorption. This conveyed an important message to the staff-the stake holders in preschool constitute a major source of knowledge, and it is a challenging opportunity to be systematically exposed to their professional world views, entailing increased appreciation of their work and dedication to the children. This entire process may generate new knowledge which cannot be obtained from another theoretical or practical source (Zilberstein, 1998).

\section{Practical Recommendations to the Staff}

\subsection{Questions for the Teacher to Ask Herself in the Beginning of the Year}

$\checkmark$ What are my professional beliefs (what is my professional credo)?

$\checkmark$ What is required of me and what is the Ministry's policy regarding new immigrants?

$\checkmark$ What are the curricula I have to become familiar with in my work with immigrant parents and children?

$\checkmark$ What are the goals of the district, the supervising authority regarding the work with immigrant parents and children?

$\checkmark$ What are this year's children's and parents cultural backgrounds?

$\checkmark$ What are the resources available to me, and what part of the resources do I have to allocate to this issue?

$\checkmark$ What else do I have to learn, and what about working with immigrant children and parents requires professional attention?

\subsection{The Teacher's Role in a Multicultural Preschool}

$\checkmark$ Setting unique, reachable goals pertaining to working with multicultural populations;

$\checkmark$ Acknowledging the nurturing of tolerance and accepting others as a leading 
value in preschool absorbing immigrant children;

$\checkmark$ Acknowledging the diversity of the child and his/her family and build the child's confidence in his/her cultural assets, as well as openness to other cultural assets, based on an egalitarian attitude and respect rather than on inferiority feelings and closing gaps;

$\checkmark$ Being familiar with ethical and cultural codes as an empowering activity;

$\checkmark$ Creating a variety of open and flexible communication channels with the parents of immigrant children. The teacher will initiate a two-way communication with the parents, explain, consult and listen out of respect to their customs and culture rather than act in a patronizing manner;

$\checkmark$ Designing a multicultural educational environment (messages on the board in a number of languages, clothing items from the children's countries of origin, books in different languages, music and songs in different languages, typical cultural representations);

$\checkmark$ Being familiar with a variety of teaching methods so as to adjust them to working with children from different backgrounds and different capabilities;

$\checkmark$ Enhancing ties with the community and the various members and professions in it so as to be able to seek their help (social workers, mediators, translators).

\subsection{Recommendations to Parents of Immigrant Children}

$\checkmark$ Remain longer with the son/daughter in the beginning of the school day, so as to enhance their self-confidence in the new environment and becoming familiar with the staff;

$\checkmark$ Showing more patience to the child while understanding his difficulties, which can dissolve tension and uncertainty and contribute to family cohesion at the same time;

$\checkmark$ Cooperate with the staff and support the educational activity for increasing mutual trust;

$\checkmark$ Show openness and willingness to learning about the new culture, customs, mentality, accepted patterns both in preschool and the community and Israeli society;

$\checkmark$ Advance in learning Hebrew in "Ulpan" or independently, which will allow for better communication with the preschool staff and the son/daughter, whose Hebrew improves due to their learning in preschool.

In sum, the grounds of success in the absorption immigrant children in preschool representing a variety of cultures consist of the construction of a work plan which helps the teacher translate a multicultural approach into practice which will provide solutions for working with culturally heterogeneous populations. The development of such a work plan is based on reflective thinking processes as reflected in this article. Moreover, a reflective discourse among the staff members will help to create better awareness of teaching and education with new knowledge created in the preschool, which might help in coping with 
unexpected situations. Therefore, it is important to increase preschool teachers' awareness of reflective thinking as a working tool.

\section{Conflicts of Interest}

The authors declare no conflicts of interest regarding the publication of this paper.

\section{References}

Becker, A. (2009). Who Did You Play with in Preschool Today? The Social World of Preschool Children. Tel Aviv: Mofet Institute. (In Hebrew)

Calhoun, E. (1994). How to Use Action Research in the Self Renewing School. Virginia: ASCD.

Clandinin, D., \& Connelly, F. (1991). Narrative and Story in Practice and Research. In D. Schon (Ed.), The Reflective Turn (pp. 258-282). New York: Columbia University.

Denham, S. A. (2010). "Plays Nice with Others": Social-Emotional Learning and Academic Success. Early Education and Development, 21, 652-680. https://doi.org/10.1080/10409289.2010.497450

Grumet, M. (1990). On Daffodils That Come before the Swallow Dares. In E. Eisner, \& A. Peshkin (Eds.), Qualitative Inquiry in Education: The Continuing Debate (pp. 101-120). New York: Columbia University.

Horowitz, T., Shamay, S., \& Iltov, Z. (2003). Implementation, Dialogue and Empowerment-Veterans and Immigrants in Katzrin. Tel Aviv: Ramot. (In Hebrew)

Keiny, S. (1994). Constructivism and Teacher Professional Development. Teacher and Teacher Education, 10, 157-167. https://doi.org/10.1016/0742-051X(94)90010-8

Letiche, H. (1988). Interactive Experiential Learning in Enquiry Courses. In J. Nias, \& S. Groundwater-Smith (Eds.), The Enquiring Teacher: Supporting and Sustaining Teacher Research (pp. 15-39). London: The Falmer Press.

Olstein, E. (1991). Hebrew Is a Tough Language for Preschool Children. Hed Hagan, 3, 233-237. (In Hebrew)

Pelto, P., \& Pelto, G. (1978). Anthropological Research of Inquiry. Cambridge: Cambridge University Press. https://doi.org/10.1017/CBO9780511607776

Schon, D. (1983). Reflective Practitioner. New York: Basic Books.

Schon, D. (1987). Educating the Reflective Practitioner. San Francisco, CA: Jossey-Bass.

Schon, D. (1991). Introduction. In D. Schon (Ed.), The Reflective Turn (pp. 1-12). New York: Columbia University. https://doi.org/10.2307/3378549

Sever, R. (2000). Воспитательница-Israeli Preschool Teachers through the Eyes of Originally CIS Parents. Hed Hagan, 4, 53-65. (In Hebrew)

Spradley, J. (1979). The Ethnographic Interview. New York: Rinehart.

Zedan, R., \& Falah, J. F. (2018). Correlation between Parental Involvement and Burnout among Kindergarten Teachers in Israel's Arab Society. British Journal of Education, Society \& Behavioural Science, 18, 1-16.

Zilberstein, M. (1998). Reflective Teaching-Conceptual Clarifications of a Teacher Education Program. In M. Zilebrstein, M. Ben-Peretz, \& S. Ziv (Eds.), Reflection in Teaching a Major Axis in Teacher Development (pp. 55-82). Tel Aviv: Mofet Institute. (In Hebrew)

Zino, G., \& Zur, H. (2009). In the Eyes of the Beholder: What Do Educators Tell about the Social Lives of Toddlers in Kindergarten? Hed Hagan, 48-56. (In Hebrew) 